\title{
Excellence in the treatment of patients with pituitary tumors
}

\author{
Mark E. Molitch ${ }^{1}$ • James W. Findling ${ }^{2}$ David R. Clemmons ${ }^{3}$
}

Published online: 9 November 2017

(C) Springer Science+Business Media, LLC, part of Springer Nature 2017

To the Editor,

We have read with interest the recent publication "Criteria for the Definition of Pituitary Tumor Centers of Excellence (PTCOE): A Pituitary Society Statement" [1]. While we agree in principle with the concept that our patients with pituitary tumors should get the best of care, medical and/ or surgical, there are some practical issues that should be considered in deciding how such care should be carried out.

A major limiting factor in restricting patients to receiving all of their care in PTCOE's is the relatively small number of neurosurgeons with the appropriate expertise in performing pituitary surgery. Not every center with endocrinology expertise in dealing with such patients has such a neurosurgeon in their own center. In such cases, a "virtual" Pituitary Tumor Center of Excellence can be created in which the endocrinologist does the initial evaluation and treatment. In fact, some aspects of evaluation can be done at another institution with expertise in that particular type of study, such as inferior petrosal sinus sampling. Ultimately, the endocrinologist refers the patient to another institution that has the expert neurosurgeon for surgery, if warranted. The endocrine team at that second institution can provide immediate postoperative care but then the additional and long-term management will be done by the original endocrinologist. One could

Mark E. Molitch

molitch@northwestern.edu

1 Northwestern University Feinberg School of Medicine, Chicago, IL, USA

2 Medical College of Wisconsin, Menomonee Falls, WI, USA

3 University of North Carolina School of Medicine, Chapel Hill, NC, USA then even conceive of the patient being referred to a third institution for radiotherapy, if that is needed.

Thus, although it may be ideal, it is not absolutely necessary to have all expertise in managing patients with pituitary tumors be in the same institution. These "virtual" Pituitary Tumor Centers of Excellence can function just as well, providing good communication is carried out between the centers. We have been carrying out this type of practice for a number of years and it has worked out very well.

Our concern in the article published is the emphasis on having all aspects of this PTCOE be at the same institution with the implication that anything other than that is to be considered as providing suboptimal care for patients. We wish to call attention to the existence of these "virtual" PTCOE's that also can provide excellent care of patients.

\section{Reference}

1. Casaneuva FF, Barkan AL, Buchfelder M, Klibanski A, Laws ER, Loeffler JS, Melmed S, Mortini P, Wass J, Giustina A, On behalf of the Pituitary Society, Expert Group on Pituitary Tumors (2017) Criteria for the definition of Pituitary Tumor Centers of Excellence (PTCOE): A Pituitary Society Statement. Pituitary 20:489-498 